\title{
Attenuation Measurement Method to Control Clay Slurries: Application of Dams Water
}

\author{
Adil Hamine \\ Laboratoire de Métrologie \\ et traitement de \\ l'information \\ Faculté des sciences. \\ Rue $445 N^{\circ} 17$, Cité des \\ A/F. Agadir / Maroc
}

\author{
Bouazza Faiz \\ Laboratoire de métrologie \\ et traitement de \\ l'information \\ Faculté des sciences, \\ B.P: 8106 Agadir 8106 . \\ Agadir / Maroc
}

\author{
Ali Moudden \\ Laboratoire de métrologie \\ et traitement de \\ l'information \\ Faculté des sciences, \\ B.P: 8106 Agadir 8106. \\ Agadir / Maroc
}

\author{
Gérard Maze \\ Laboratoire d'Acoustique \\ Ultrasonore et \\ d'électronique (UMR \\ CNRS 6068) \\ 25 rue Philippe Lebon BP \\ 112376063 LE HAVRE
}

\begin{abstract}
We propose to study the behavior of diluated suspensions of clay and non colloidal particles by a combination of experiments. We plan to study these diluate particulate systems by changing the masse fraction of clay. We have developed a technique based on the ultrasound, by measuring ultrasonic attenuation waves in clay slurries. This technique makes it possible to control in real time the presence of the clay grains whose dimension is about 10 micron, using an interface conceived under Labview program. The slurries with different weight of clay were controlled. The detection of weak amount of clay's grains and colloid were provided by the transducer $30 \mathrm{Mhz}$. High sensitivity is obtained by analyzing the attenuation measurements founded from multiple paths through the slurry. The experimental results obtained show that the attenuation of waves due to particles varies linearly with mass fraction and the frequency of transducers. Therefore, such measures of the attenuation at a given frequency give the concentration of clay in the suspension. These frequency charts will be used for the quality control of the dam's water.
\end{abstract}

\section{General Terms}

0.N.E.P: Office National de l'eau Potable, (National office of drinking water).

FFT: Fast Fourier Transform.

\section{Keywords}

Clay suspension characterization, diluate clay suspensions, ultrasonic attenuation, attenuation measurement method, clay concentration in distilled water, clay's slurries control, dam's water measurement.

\section{INTRODUCTION}

Using ultrasound measurements were carried out to characterize the liquid, solid and gas for over 60 years. The need for compact, non invasive, real time measurement of density and concentration for waste slurries of clay, fostered the development of an ultrasonic sensing technique based on the reflection and transmission of ultrasonic signal at the sensor-fluid interface. While the ultrasonic attenuation spectrometers witch available on the market have was entirely used, [1].But imprecise measurements of these devices require us to use another method of measuring the scale of our laboratory. One problematic area is the region of application of the particle size or smaller than 10 micron. Most work applies to the measurement of ultrasonic process by focusing on the application of density, flow measurement and detection interface. The dam water contains different sizes of clay grains. The knowledge of the concentration of clay present in water will make possible to optimize the addition of the chemicals products which allows the clay recovery. The suspensions of clay studied are between 5 and $50 \mathrm{~g} / \mathrm{l}$. Theses concentrations range were proposed by (0.N.E.P) the National Office of Drinking Water in the region of Agadir city in Morocco. Each concentration corresponds at an output rate of water into the basins and tanks treatment, (see Table 1).

Table1. Clay concentrations versus barrier water flow

\begin{tabular}{|c|c|c|}
\hline Clay concentrations (g/l) & \multicolumn{2}{|c|}{ Water flow $\left(\mathrm{m}^{3} / \mathbf{s}\right)$} \\
\hline 5 to 10 & 50 & Maximum flow \\
\hline 10 to 20 & 38 & Average flow \\
\hline 20 to 30 & 19 & Low flow \\
\hline 40 to 50 & 0 & Water cut \\
\hline
\end{tabular}

\section{TECHNIQUE OF MEASURING THE}

\section{ATTENUATION}

Ultrasonic velocity is the distance which the wave cast through the sample for a unit of time. The attenuation coefficient is the measurement of the reduction in the amplitude of ultrasonic wave for a unit distance, [2-3]. (see Equation 1).

$$
\alpha=-\frac{1}{d} \ln \left(\xi_{r e f} \frac{A_{d}}{A_{0}}\right)
$$

$A_{0}$ is the ultrasonic amplitude at the position $\mathrm{x}=0$ $A_{d}$ is the amplitude after having cover a distance $\mathrm{x}=d$ $\xi_{\text {ref }}$ is the ratio of the acoustic impedances of the extreme mediums.

The attenuation coefficient of the sample is given with same preceding manner. If we use only one transducer in the 
reflexion method, we must replace the distance $d$ by $2 d$ in the (Equation 1), because the wave made two alleys and return in the container, (see Figure 1), [4].

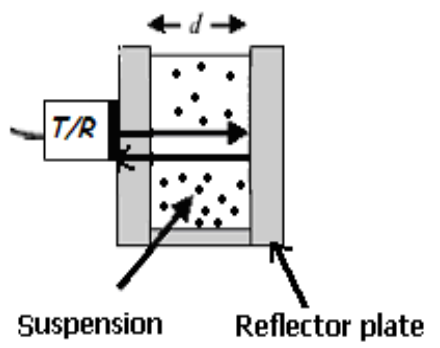

Fig 1 : Wave trajectory into the container

The distribution of the particles and their size in slurries are connected, with the determination of the attenuation coefficient [5], or/and the velocity of sound.

\section{SLURRIES PROPERTIES}

Slurries of clay properties include mixture density $\left(\rho_{m}\right)$, mass fraction $\left(C_{m}\right)$ or volume fraction $\left(C_{v}\right)$, mean size particle of clay's grains $\langle a\rangle$, and bulk density of the solid $\left(\rho_{c}\right)$. The mass of the slurry $\left(M_{m}\right)$ is: $M_{m}=M_{f}+M_{c}$, where $M_{f}$ is the mass of fluid and $M c$ is the volume of the particulate of clay. The volume of slurry $\left(\mathrm{V}_{\mathrm{m}}\right)$ is: $V_{m}=V_{f}+V_{c}$, where $V_{f}$ is the volume of fluid and $V_{c}$ is the volume of the particulate of clay's grains. The mass fraction of slurry is determined by the ratio, (see Equation 3).

$$
C_{m}=\frac{M_{c}}{\left(M_{c}+M_{f}\right)}=\frac{\rho_{c}\left(\rho_{m}-\rho_{f}\right)}{\rho_{m}\left(\rho_{c}-\rho_{f}\right)}
$$

fraction relationship is $C_{v}$, (see Equation 4).

$$
C_{v}=\frac{C_{m}}{\left[C_{m}+S\left(1-C_{m}\right)\right]}
$$

Where $S$ is the relative density of clay's grains $\left(\rho_{p} / \rho_{f}\right)$. The volume fraction is proportional to the number of particles per unit volume $(n)$. Suppose there are $N$ particles in the total volume $\left(V_{T}\right)$ and each particle occupies a given volume $\left(V_{P}\right)$. The average particle size of clay's grains is about $10 \mu \mathrm{m}$. The density of the slurry was obtained also by weighing a known volume of clay. The density of the slurry was also obtained from the known weight percentage of the slurry, the density of clay $\left(2680 \mathrm{~kg} / \mathrm{m}^{3}\right)$, and the density of water $\left(1 \mathrm{~kg} / \mathrm{m}^{3}\right)$, [6]. When the particulate of clay is insoluble in the liquid, the relationship is given by using (see Equation 5). For process control for a given type of particulate in the slurry, the instrument calibration provides the attenuation as a function of weight percentage. When the instrument operates in-line, the attenuation in turn is related to the weight percentage of clay's grains in the slurry.

$$
W t \%=\frac{\rho_{w}\left(\rho_{s}-\rho_{w}\right)}{\rho_{w}\left(\rho_{c}-\rho_{w}\right)} \times 100 \%
$$

Where $\rho_{w}$ is the density of water, $\rho_{c}$ is the density of the clay, and $\rho_{s}$ is the density of the slurry.

\section{EXPERIMENTAL DEVICE}

The measuring apparatus used in this work, made up of : a generator of pulse, an oscilloscope, a container and transducer (see Figure 2).

Where $\rho_{f}$ is the fluid density. The corresponding volume

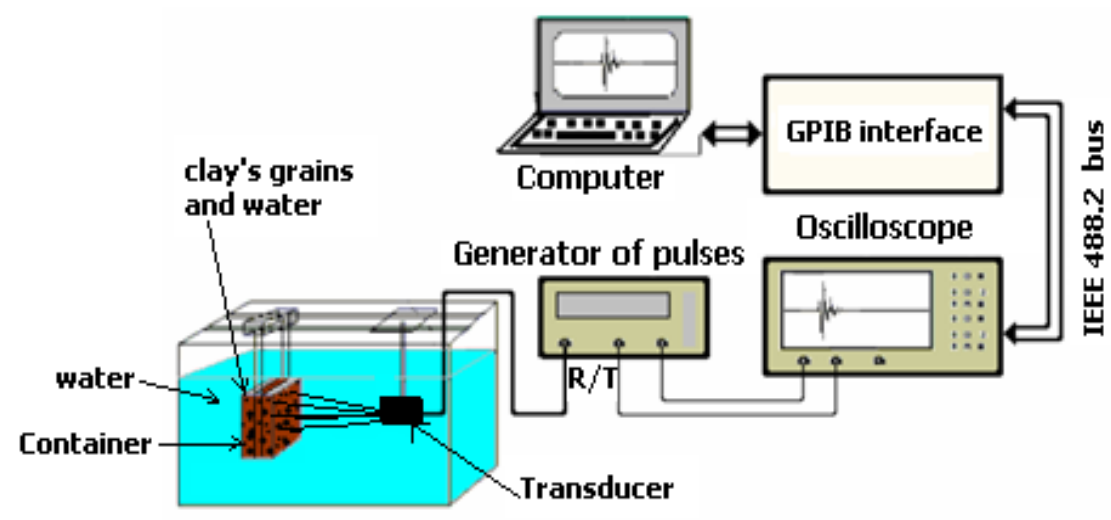

Fig 1: Experimental device, (method by reflexion)

\section{REAL TIME CONTROL OF THE CLAY'S PARTICLES SEDIMENTAION}

We begin the control with the acquisition of the signals illustrated on the screen of the oscilloscope by an application under the graphic programming language Labview, [7]. The developed interface makes it possible to specify the number of acquisitions wanted during the experiment and time separating two successive acquisitions. The Labview program collects 10 signals each time and carries out an average to neutralize the interfering signals. The resulting signal represents for the user only one acquisition, [8-9]. An example of an experimental signal retrodiffused by the container which contains the sample is shown in (see Figure 3).

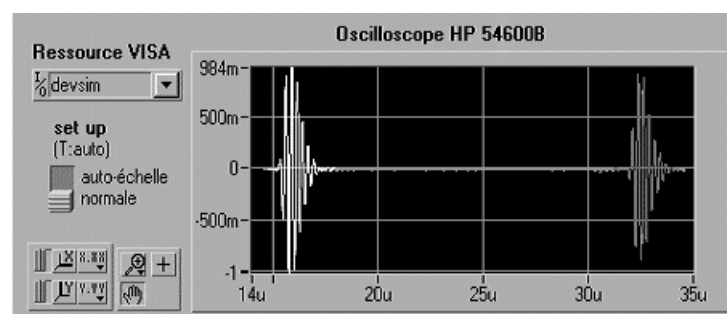

Fig 3: Signal retrodiffused by the container

This signal is composed of two echoes $A_{2}$ and $A_{4}$ shown successively from left to right on the figure 3 . This signal is captured starting from the oscilloscope by the Labview 
program developed. We have noted that the water was characterized only by the echoes $\mathrm{A}_{2}$ (reflexion on the interface between the second face of plate 1 , and the mixture of clay's grains/water), and $\mathrm{A}_{4}$ (reflexion with the interface between the mixture of clay's grains/water, and the first face of plate 2). Then, the program separates the echoes by temporal windows by taking only the echo $\left(\mathrm{A}_{2}\right.$ and $\left.\mathrm{A}_{4}\right)$ however the sites of echoes compared to time (X-coordinate) remain unchanged. The user has the possibility of choosing the first time manually the echo which will take a different color thereafter. The continuous spectra of phase of the echoes $\mathrm{A}_{2}$ and $\mathrm{A}_{4}$ are presented on the figure 4 .

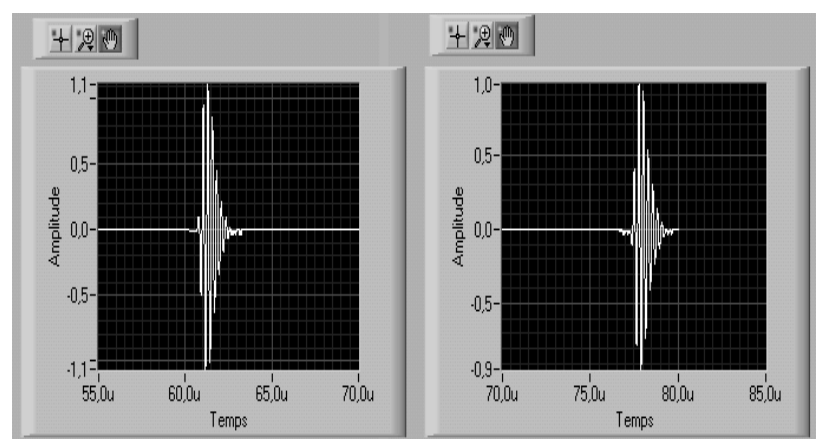

Fig 4: Filtered signal of the echoes $\mathrm{A}_{\mathbf{2}}$ and $\mathrm{A}_{\mathbf{4}}$

The spectral amplitudes, of the echoes $\mathrm{A}_{2}$ and $\mathrm{A}_{4}$, are determined by the application of the FFT to the signals of figure 3. The spectra of amplitudes of the two echoes $A_{2}$ and $\mathrm{A}_{4}$ are respectively presented on figure 5 .

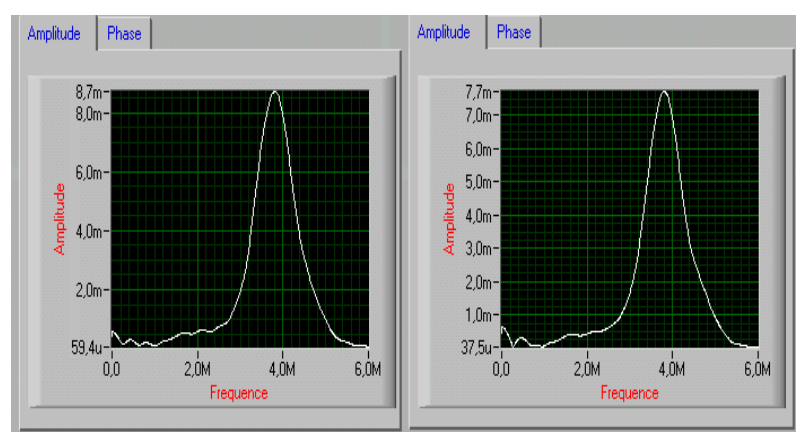

Fig 5: Spectral amplitude of the echoes $A_{2}$ and $A_{4}$

\subsection{Measure the attenuation in suspensions}

The attenuation of sound in water and clay mixture is given by the equation $6,[10-11]$.

$$
\alpha=-\frac{1}{2 d} \ln \left(\xi_{r e f} \frac{A_{4}}{A_{2}}\right)
$$

With $\xi_{\text {réf }}=\frac{\left(Z_{p g}+Z_{\text {Susp }}\right)^{2}}{4 Z_{P g} Z_{\text {Susp }}}$ and

$Z_{P g}=\rho_{p g} \cdot C_{p g}, Z_{p g}$ is the acoustic impedance in the Plexiglas.

$Z_{e a u+\text { arg }}=\rho_{e a u+\text { arg }} \cdot C_{e a u+\text { arg }}, Z_{\text {Susp }}$ is the acoustic impedance in suspension. [12-13-14].

\section{RESULTS AND DISCUSSIONS}

We prepare the suspension with the method described above. Theses suspensions analyzed were prepared from known quantities of dry clay and distilled water. After sufficient agitation, which provides the average distribution of clay's particles per volume element, we send a pulse on the vessel containing the suspension, we allowed the suspension settled.

\subsection{Attenuation measurement on the scale frequency of 4 to $8 \mathrm{MHz}$}

Attenuation was calculated based on the frequency of 4 to 8 $\mathrm{MHz}$ with an increment of $1 \mathrm{MHz}$ for five concentrations $(5 \mathrm{~g} / 1,10 \mathrm{~g} / \mathrm{l}, 20 \mathrm{~g} / \mathrm{l}, 30 \mathrm{~g} / \mathrm{l}$ and $40 \mathrm{~g} / \mathrm{l})$. For each suspension, the data were obtained for a first measurement M1, followed by a second measurement M2 after 12 hours, because after this period in distilled water the clay's grains swell and their sizes become larger, which will influence the attenuation values (see Figure 6). The Analysis of these curves shows that the attenuation increases when the clay concentration increases. And that in each case, the data of M2 are higher than those obtained in M1. This is explained by the fact that the clay's particles reacted with distilled water, causing a slight increase in the volume of clay's particles, and a small amount of air bubbles in the suspensions were contributed to rising values of the attenuation data M2.

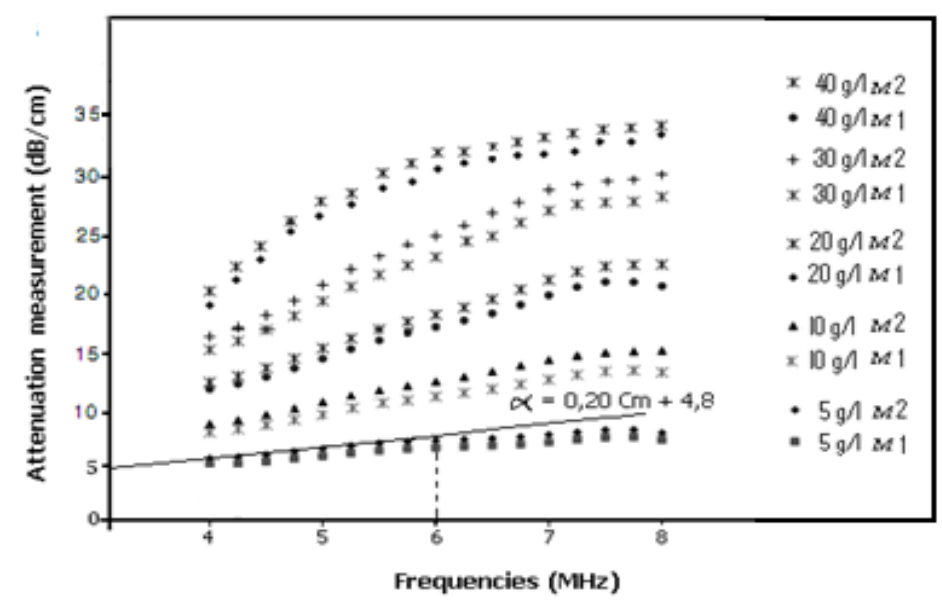

Fig 6: Attenuation curves as a function of the frequencies, for two measurements M1 and M2 after (12 hours) 
displays a straight line. For example, the concentration of $5 \mathrm{~g} / \mathrm{l}$ at the frequency $6 \mathrm{MHz}$, the slope is given by the equation 7 .

$$
\alpha=0.2 \mathrm{C}_{\mathrm{m}}+4.8
$$

Where the slope is expressed in $\left(\mathrm{dB} / \mathrm{cm} \mathrm{C}_{\mathrm{m}}\right)$. Indeed, similar results were found for the other frequencies of 3 to $5 \mathrm{MHz}$, where the slopes respectively are $(0.23-0.25-0.29)$. Therefore, a measure of the attenuation at a given frequency gives the amount of clay present in the suspension, and vise versa. We also note that the last measurement $40 \mathrm{~g} / \mathrm{l}$, we note that the linear aspect disappears, because we fall within the range of concentrated suspension, and interactions forces begin to take place in the suspension. These charts built will serve us to control the amount of clay present in each suspension, and optimize the addition of chemicals products that will serve us to recover the clay and the quality control of the dam's water.

\subsection{Attenuation measurement at high frequency $30 \mathrm{MHz}$ (transmission method)}

The transmission method differs in principe from the reflection method, it consist to measure the difference of attenuation $\Delta \alpha$ versus the time of sedimentation. The difference of attenuation was followed for three concentrations of clay suspensions $(0.5 \mathrm{~g} / \mathrm{l}, 4 \mathrm{~g} / \mathrm{l}$ and $40 \mathrm{~g} / \mathrm{l}$, respectively on the figures (Fig 7.a), (Fig 7.b) and (Fig 7.c).

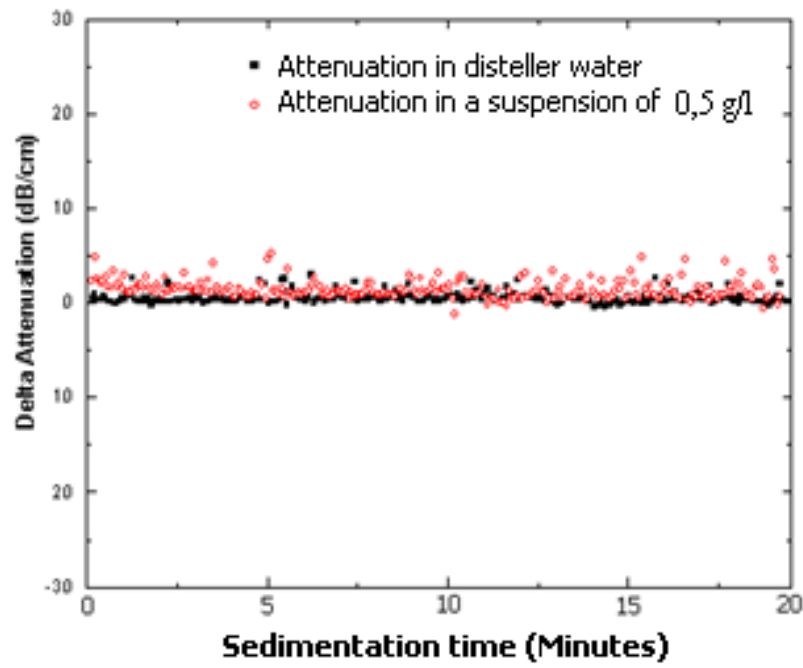

Fig 7.a: Attenuation measurement versus sedimentation time for a suspension of $0.5 \mathrm{~g} / \mathrm{l}$

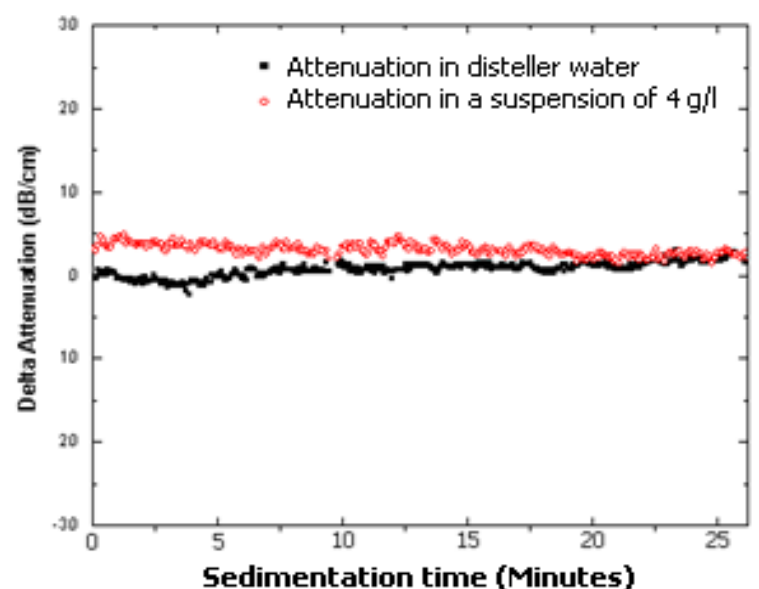

Fig 7.b: Attenuation measurement versus sedimentation time for a suspension of $4 \mathrm{~g} / \mathrm{l}$

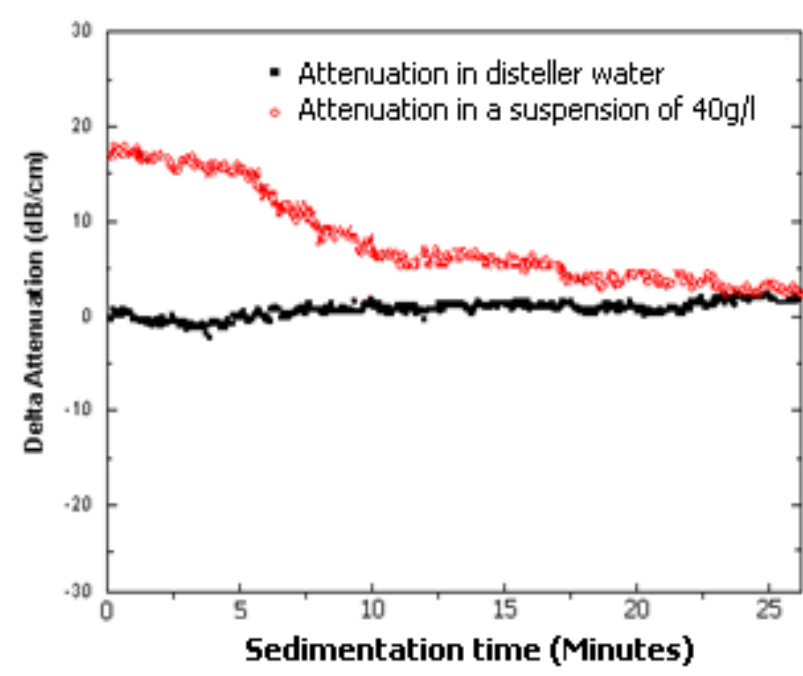

Fig 7.c: Attenuation measurement versus sedimentation time for a mixture of $40 \mathrm{~g} / \mathrm{l}$

The analysis of these figures shows that when the concentration of clay increases in distilled water, the difference of attenuation $\Delta \alpha$ increases. We note that the linear characters of the last curve above disappear. The curve shows attenuation fall during three minutes of the starting experiment, because the suspension becomes very concentrated in clay and the interactions forces between clay's grains begins to take place.

The transducer of $30 \mathrm{MHz}$ is very sensitive for detecting the presence of small amounts of clay. We can use high frequency transducers to detect colloids and very small clay particles.

\section{Conclusion}

The results obtained show that the attenuation of ultrasonic varies linearly almost with frequency scale between 4 to 8 $\mathrm{MHz}$ with $1 \mathrm{MHz}$ increment and this only for the low levels of clay. We also note that the attenuation values increase as a function of the amount quantities of clay in suspension. Therefore, a measure of the attenuation at a given frequency in any suspension gives the quantity of clay present in the suspension. These charts built will serve us to control the small quantity of clay present in any suspension, and optimize the addition of chemicals products that will serve us to recover the clay grains after having promote their agglomeration. These results will serve us in our future field work for the quality control of the dam's water.

Using a transducer with high frequency $30 \mathrm{MHz}$ used to detect fine clay particles and colloids. In this case also, we note that the difference of attenuation varies linearly with the clay mass fraction in each suspension. Such measures may indeed be used for detecting contaminants and allow to the very precise measurements of the small concentrations of clay in any suspension. Finally, we also note that when we increase the quantity of clay in suspension, the linear character of the curves disappear because the interaction between particles strengths and becomes very important.

In this case, if we want to study such suspensions, it is necessary to use other ultrasonic methods of characterizing concentrated clay's suspensions. 


\section{ACKNOWLEDGMENTS}

Our thanks to all agents of the National Office of Drinking Water of the Agadir region, (O.N.E.P) for their cooperation, and all person who have contributed towards development of this article.

\section{REFERENCES}

[1] F. Larrarte, P. François "Attenuation of an ultrasonic beam by suspended particles and range of acoustic flow meters in sewer networks".Water Sci Technol. (2012); 65(3):478-83.

[2] A. Richter, F. Babick, M. Stintz, "Polydisperse particle size characterization by ultrasonic attenuation spectroscopy in the micrometer range", Ultrasonics 44 (2006), e483-e490.

[3] F.G. Eggers,U. Kaatze, "Broad band Ultra-sonic Measurement. Techniques for Liquids", Meas. Sci. Tech., 7, 1- 19, (1996).

[4] B. Faiz, "Contrôle ultrasonore de la prise en masse d'un yaourt et d'une résine époxy", Thèse de Doctorat d'Etat, Agadir, Maroc, (1997).

[5] U. Riebel, F. Loffler, "The Fundamentals of Particle Size Analysis by mean of Ultrasonic Spectrometry", Part. Part. Syst. Charact., 6, 135-143, (1989).

[6] N. Taifi, F. Bakkali, B; Faiz, A Moudden, G Mase and D. Décultot. Meas .Sci. Technol. 17.281-287. (2005).

[7] National Instrument, "Initiation à LabVIEW", Édition de Février (2001)
[8] D. K. Mak, "Comparison of various methods for the measurement of reflection coefficient and ultrasonic attenuation", British Journal of NDT, (1991); 33(9), pp. 441-448.

[9] P. Mougin, D. Wilkinson, K.J. Roberts, R. tweedie, characterization of particle size and its distrubution during the crystallization of organic finechemical products as measured in situ using ultrasonic attenuation spectroscopy, J. Acoust. Soc. Am. 109 (1) (2001) 274 282.

[10] Mc Clements D. J., "Ultrasonic NDT of foods and drinks. In International advances in Nondestructive Testing, ed. McGonnagle", W. J., Vol. 17. Gordon and Breach Science. Yverdon, Switzerland, pp. 63-95, (1994).

[11] Mc Clements D. J., "Advances in the application of ultrasound in food analysis and processing", Trends Food Sci. Technol., 6, 293-299, (1995).

[12] Povey M. J. W. \& McClements D. J., "Ultrasonics in food engineering: part I. Introduction and experimental methods". J. Food Engng, 8, 217-245, (1988).

[13] T. J. Lee, K. Nakano and M. Matsumara, "Ultrasonic irradiation for blue-green algae bloom control", Environmental Technology, vol. 22 (4), pp. 383-390, Apr. (2001).

[14] N. Gandilhon, O. Adam, M. Louis"UsingPassive Acoustics for Marine Mammal Observations". J.irephy; Multidisciplinary Observatories, Materials and Software February (2010) ,Vol. 4. n. 1;pp. 20-28. 